\begin{tabular}{l|l} 
Revista Duazary & ISSN: $1794-5992$
\end{tabular}

Vol. 13

No. 1

$40-46$

Enero - Junio de 2016

\title{
ÉBOLA: ¿ENFERMEDAD VIRAL O PATOLOGÍA SOCIAL?
}

\author{
EBOLA: VIRAL DISEASE OR SOCIAL PATHOLOGY?
}

\section{TÍTULO CORTO: ÉBOLA: ¿ENFERMEDAD VIRAL O PATOLOGÍA SOCIAL?}

\author{
José David Romero-Rueda ${ }^{1}$, Mauricio Torres-Tovar ${ }^{2}$
}

Recibido en febrero 13 de 2015

Aceptado en junio 10 de 2015

\section{RESUMEN}

El Ébola es una enfermedad infecciosa viral altamente letal que puede ser producida por una de sus varias cepas, el 8 de agosto del 2014 la Organización Mundial de la Salud la declaró como una "emergencia de salud pública de interés internacional" debido al brote de la cepa Zaire que ha afectado a varios países de África occidental Guinea Conakry, Liberia, Sierra Leona, Malí y Nigeria, y que deja a enero de 2015 un saldo de más de 20.000 personas infectadas y al menos 8000 muertes. El presente artículo reflexiona sobre la situación actual de la epidemia, sus consecuencias particulares sobre el personal de atención en salud y su relación con los determinantes en salud de dichas poblaciones.

Palabras clave: Ébola virus; epidemias; salud pública; factores epidemiológicos

\section{ABSTRACT}

Ebola is an infectious disease highly lethal caused by one of the Ebola virus strains, this year on August $8^{\text {th }}$, the World Health Organization declared the Ebola outbreak a 'public health emergency of international concern' because the outbreak of Zaire strain who affected several countries in western Africa -Guinea Conakry, Liberia, Sierra Leone, Nigeria - and have already infected more than 20000 people and killed at least 8000 . This paper reflects on the epidemic current context, their specific consequences over the health staff and the relationship between the determinants of health of such communities.

Keywords: Ebolavirus; Epidemics; Public Health; Epidemiologic Factors 


\section{INTRODUCCIÓN}

$\mathrm{E}_{\mathrm{p}}^{\mathrm{n}}$ el contexto actual del mundo globalizado, la posibilidad de que las enfermedades infecciosas viajen fácilmente de un lado a otro del planeta tiene altas probabilidades. La reciente epidemia del Ébola siguió esta dinámica notablemente a tal grado de llegar a ser declarada "emergencia de salud pública de interés internacional" por la Organización Mundial de Salud (OMS).

El Ébola es una enfermedad hemorrágica viral, presente inicialmente en animales (murciélagos y gorilas) y luego propagada a seres humanos por contacto directo de persona a persona, con una alta letalidad, que según la OMS es de 70\%; A la fecha no existe ningún medicamento para su tratamiento ni tampoco vacuna para su prevención.

Este artículo reflexiona sobre la situación actual de la epidemia, sus consecuencias particulares sobre la salud del personal sanitario y la relación con los determinantes en salud en las poblaciones africanas que vienen padeciendo la epidemia, tratando de responder la pregunta de si el Ébola es principalmente una enfermedad producto de una infección viral o más que ello, una patología de la desigualdad e inequidad social.

\section{¿Qué es el Ébola?}

La enfermedad por el virus del Ébola conocida antes como fiebre hemorrágica del Ébola es una enfermedad infectocontagiosa viral producida por cualquiera de las cinco cepas de la familia filovirus, es una entidad poco contagiosa empero altamente letal ${ }^{1}$. El 8 de agosto del 2014 la organización mundial de la salud la declaró una emergencia de salud pública de interés internacional debido al brote de la cepa Zaire, que afectó a varios países de África occidental y que dejó un saldo de 20.747 personas infectadas y 8235 muertes a comienzos de enero de $2015^{2,3}$ (Figura 1). El virus del Ébola es un patógeno zoonótico, se cree que el reservorio más probable son los murciélagos frugívoros, sin embargo este hecho supondría una difícil circulación entre las poblaciones humanas por su exiguo contacto con dicho reservorio ${ }^{4}$; de este punto surge la pregunta crítica, ipor qué entonces estas comunidades se han contagiado reiteradamente en los últimos años con un virus de tan difícil transmisión?

\section{¿Cómo se transmite el virus?}

El contagio de este virus ocurre mediante contacto directo con fluidos corporales infectados; de aquí se puede inferir que la situación de convivencia en hacinamiento y el déficit nutricional crónico son el blanco de vulnerabilidad de las poblaciones afectadas y que a su vez favorecen la propagación y sostenimiento del brote ${ }^{5}$.

\section{¿Es posible controlar la propagación del virus?}

De los más de 20 brotes reportados del virus del Ébola desde su identificación en 1976 en Sudán y en la República Democrática del Congo, se calculó menos de 1600 muertes antes del brote del 2014 en África Occidental Guinea, Liberia, Sierra Leona y Nigeria con conteos que iban desde un puñado de casos en regiones tropicales del África subsahariana hasta 425 en el brote en Uganda del 2000-20016; sin embargo, diversas investigaciones indican un patrón de transmisión, en el que se destaca el confinamiento a una región delimitada de tipo rural, en donde los brotes son generalmente contenidos con medidas rutinarias de salud pública tales como identificación de casos, seguimiento de los mismos, aislamiento y cuarentena ${ }^{5,7}$.

Nigeria fue declarada, según la Organización Mundial de la Salud, libre de Ébola por no reportarse ningún caso durante el doble del tiempo de incubación (42 días) ${ }^{7}$, entonces ¿Nigeria es la excepción del patrón de transmisión? Lo anterior sugiere que el sistema de salud es más estructurado, proveído por un estado con una mejor economía, que supo aplicar las medidas básicas de salud pública para la contención de la epidemia.

Recientemente, se ha hablado de varios ensayos de vacunas contra el Ébola, entre ellas un "cóctel" de anticuerpos humanizado de ratón ("ZMapp") 4 , el cual ha demostrado ser prometedor en estudios preclínicos. Lo cierto es que este avance biotecnológico solo tuvo interés cuando la epidemia ya se había expandido globalmente; evidentemente habrá gente dispuesta a comprar la vacuna, antes no tenía sentido mercantil ya que las comunidades pobres africanas no son clientela para la industria farmacéutica.

De cualquier manera, es muy improbable que una vacuna milagrosa vaya a terminar la epidemia del Ébola, empero serán las prácticas de salud pública, el compromiso con las comunidades afectadas, la solidaridad y el soporte internacional, los pilares para vencer esta epidemia; es imperativo que la falta de liderazgo, la coordinación deficiente y la incapacidad operacional por parte de los países miembros de las naciones unidas cese, esta epidemia es una amonestación a la comunidad internacional para que tengan en cuenta que aunque no 
sean países percibidos como de relevancia económica o política, se deben compartir finalmente tanto las beneficios y las adversidades del planeta en que se vive, que estos terminarán afectándonos directamente. La solidaridad con estos países no puede hacerse esperar hasta una amenaza inminente de seguridad a la salud global, ¿cuántas tragedias son necesarias para entender que es obtusa la perspectiva de limitar la respuesta a contrarrestar pacientes infectados fuera de África?; hay que controlar la transmisión del virus de raíz, hay que cuidar de los pacientes en África occidental.

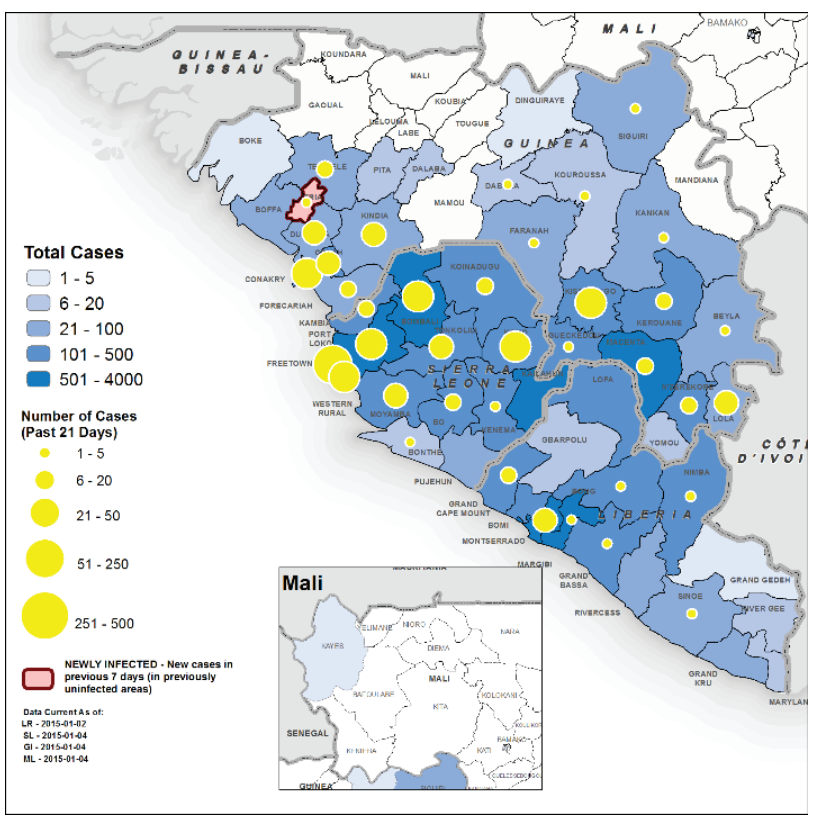

Figura 1. Distribución geográfica de los casos acumulados en los últimos 21 días en Liberia, Guinea Conakry, Sierra Leona y Malí. *Imagen tomada de la página de la OMS el 7 de enero del 2015 (www.who. int/csr/don/archive/disease/ebola/en) («WHO | Ebola virus disease», s. f.).

\section{Economías empobrecidas}

Existen características económicas que los países asolados por la epidemia del Ébola comparten entre sí, por lo que 42 se procurara una mirada general de ellas.

\section{Guinea}

Guinea es el segundo productor mundial de bauxita y aún cuenta con la mayor reserva de bauxita que se estima en 29 mil millones de toneladas. El país también cuenta con reservas significativas de hierro, oro y diamantes, sin embargo, ha sido incapaz de sacar provecho de su potencial mineral debido a problemas como la corrupción rampante, la deficiente infraestructura, la incertidumbre política y la industria extranjera explotadora de recursos naturales.

La economía de Guinea depende de la ayuda internacional, es por ello que la situación desde 2008 se vio deteriorada, tras el golpe de estado que siguió a la muerte del presidente Lansana Conte. Los mayores proveedores de fondos del ámbito internacional (entre ellos el Banco Mundial, el G-8 y el Fondo Monetario Internacional) redujeron sus programas de desarrollo de forma considerable. Posteriormente, la Junta Militar que operó hasta las primeras elecciones democráticas debilitó sensiblemente la economía de Guinea, llevando las tasas de inflación y deuda del país a niveles muy altos ${ }^{8}$.

\section{Liberia}

El pueblo liberiano no es ajeno a las consecuencias del conflicto armado interno que han padecido en carne propia, la violencia ha afectado primariamente la economía liberiana y ha conducido al estado a una continua dependencia de ayuda extranjera; además esta asistencia internacional y la inversión han estado supeditadas por la incapacidad de los gobiernos de ser transparentes y de luchar contra la corrupción política?.

La combinación es fatal, violencia más corrupción, un circulo que desemboca en la imposibilidad de un estado fallido de garantizar soberanía y cobertura de las necesidades de su población, las consecuencias nocivas no se hacen esperar.

\section{Sierra Leona}

Sierra Leona es vulnerable a las fluctuaciones de los precios internacionales de los productos básicos. Al igual que Guinea y Liberia, el país depende de la ayuda externa para cubrir sus necesidades presupuestarias; las remesas del extranjero constituyen una cuarta parte de los ingresos totales. Aunque tiene importantes recursos naturales minerales en bauxita, rutilo y diamantes, la infraestructura socioeconómica se halla empobrecida y el desarrollo económico se ha entorpecido tras una guerra civil que ha durado nueve años ${ }^{10}$.

Se puede abstraer que estos tres países cuentan con una riqueza de recursos naturales formidable, sin embargo 
en la otra cara de la moneda se tienen altos índices de corrupción, guerras civiles, inestabilidad política, índices extremos de pobreza, explotación industrial insostenible de los recursos naturales, sobreexplotación de la clase obrera y dependencia de ayuda extranjera; estos factores aunados a un sistema de salud deficiente producto de un estado fallido configuran el contexto "ideal" para que su población enferme y muera indignamente en medio de una epidemia que se contrarrestaría mediante medidas básicas de salud pública.

La pobreza empuja a la gente a extender su rango de actividades para sobrevivir, introduciéndose más profundamente en el bosque para abarcar una mayor franja de territorio y de especies de caza, para encontrar madera para hacer carbón, y más profundamente en las minas para extraer minerales, aumentando su riesgo de exposición al virus del Ébola y a otros agentes zoonóticos en estos lugares remotos. La situación se agrava, cuando la persona infectada se presenta en un dispensario sanitario empobrecido y abandonado, donde el suministro de guantes, agujas limpias y desinfectantes no está asegurado; dejando a los pacientes y a los trabajadores sanitarios igual de vulnerables a la transmisión nosocomial. El ciclo se amplía más extensamente, si las personas infectadas en el hospital retornan a sus hogares mientras incuban el virus del Ébola.

\section{El efecto del fallo del gobierno y pobres sistemas de salud}

Décadas de gobiernos ineficaces y corruptos han dejado a estos países en una situación de desarrollo estancado. Guinea es uno de los países más pobres del mundo, situado en el puesto 178 del ranking de 187 países, según el Índice de Desarrollo Humano del Programa de Desarrollo de las Naciones Unidas (justo detrás de Liberia [174] y Sierra Leona [177]). Más de la mitad de los guineanos viven por debajo del umbral nacional de la pobreza y alrededor de un $20 \%$ vive en situación de pobreza extrema ${ }^{11}$.

Los brotes virales de Ébola suceden en áreas en las que la economía y el sistema de salud pública son confluentemente ineficaces, en poblaciones que han sido diezmadas por años de guerras civiles y adolecen bajo el amparo y la condición de sus respectivos estados fallidos.

La OMS reconoce que la región africana sufre la exclusión de los circuitos comerciales que impiden la participación de los países pobres en los mercados internacionales. Sólo el 10\% de los fondos dedicados a investigaciones médicas (para medicamentos y vacunas) tratan de encontrar un remedio para el $90 \%$ de las enfermedades que asolan el continente.

Lo más alarmante es que las condiciones sanitarias y las enfermedades que sufren los africanos no son sólo curables, sino prevenibles. El informe denuncia que la mayoría de las muertes en esta región podría ser evitada si pudieran acceder a una salud básica.

La salud precaria de África es un síntoma, como tantos otros, de las condiciones paupérrimas en las que África está sumida. El $76 \%$ de la población subsahariana vive con menos de dos PIB de esta zona ha descendido un $13 \%$, al doblarse la cantidad de gente que ha pasado a vivir con un dólar al día (de 164 a 314 millones). Esta tendencia continuará en los próximos años en el África subsahariana, donde se espera un nuevo incremento que puede ser aún más brutal que el anterior.

Con un brote que está alcanzando su máxima intensidad y con gobiernos ineficaces y mal dotados, el reto abarca a personas infectadas cruzando las permeables fronteras de los países implicados y la necesidad de una coordinación intergubernamental junto con los desafíos logísticos que suponen áreas remotas con pobres infraestructuras y redes de comunicaciones.

\section{Trabajadores de la salud en riesgo}

"Esta tragedia de las muertes de los que luchan contra esta enfermedad mortal junto con la pérdida de vidas de tantos otros son un golpe terrible en la lucha contra la epidemia y apunta a la necesidad urgente de una acción inmediata y concreta para controlar su propagación antes de que se encuentre fuera de control. Con casi 3.000 empleados en la región y teniendo en cuenta la rápida propagación de la enfermedad dentro de las comunidades y la lenta respuesta internacional, es probable que los trabajadores de la salud de Médicos Sin Fronteras (MSF) o sus familiares se infecten con el Ébola”12.

El caso del Dr. Brisbane, médico liberiano internista y urgenciólogo, quien se formó en Alemania en los años 70, que volvió a su país para ejercer en el servicio de urgencias del centro John F Kennedy, es triste y lamentable. Murió a causa de una infección con Ébola, evitable si hubiesen existido los recursos para conservar las normas básicas de bioseguridad en el centro de salud donde trabajaba. Murió dignamente manteniéndose siempre al servicio de 
sus pacientes, puesto que pudiendo hacerlo, nunca quiso abandonar el hospital, ejemplo de virtud y de vocación ${ }^{13}$.

Lo que se esconde detrás de su muerte es realmente alarmante, el Dr. Brisbane lo advertía con preocupación antes de morir, "El sistema de salud no cuenta con los recursos mínimos necesarios para responder ante una epidemia de estas características". Muchas personas como el doctor Brisbane se encuentran tratando de combatir esta epidemia en África, sin embargo, sin los recursos materiales mínimos para hacerle frente, y sin las decisiones políticas que modifiquen el orden socioeconómico de estos países para que se permita tener un sistema de salud digno no son más que esfuerzos románticos fútiles que no verán la recompensa de su coraje manifestada en el final de la epidemia.

\section{Una perspectiva desde la salud pública de la epidemia}

Entre muchos factores y variables que sinérgicamente han desembocado en una epidemia de Ébola con devastadoras consecuencias saltan a la vista el deficiente sistema de salud, sus insuficientes recursos para atención primaria, la ausencia de un sistema de vigilancia epidemiológica eficaz, incapacidad de aislamiento de casos sospechosos y adecuado tratamiento de soporte; todo esto ha sido evidenciado en la alta tasa de mortalidad que deja a su paso esta epidemia.

Tres intervenciones básicas han parado los brotes pasados de Ébola y serían eficaces en estos países, estos son: el extensivo hallazgo de casos y contactos, la respuesta efectiva a los pacientes y las intervenciones preventivas ${ }^{14}$; ha sido la deficiencia de estas medidas, producto de pésimos sistemas de salud, incorporado a ello el peso de los determinantes sociales como la injusta distribución de la tierra y la exclusión del acceso a la vivienda y hábitat dignos ${ }^{15}$ que son los determinantes de otros graves problemas de salud crónicos en estas poblaciones que han dilatado anormalmente la duración de esta epidemia.

\section{Una patología social}

44 La situación descrita acá sobre el Ébola nos recuerda el análisis que hiciera Rudolf Virchow a mediados del siglo XIX sobre la epidemia de tifus, al esclarecer que era una epidemia de la pobreza y que las medidas de intervención no eran principalmente de carácter médico, sino social.

El Ébola es producto de una determinación social, económica y política que en su dominio general, es decir estructural, se relaciona con el conjunto de políticas internacionales de tipo económico y social que han acelerado la acumulación de capital a partir de aumentar el despojo con una explotación intensiva de los recursos naturales de los países y debilitar sus políticas sociales de salud, protección social, educación, alimentación, entre otras ${ }^{16-18}$. Estas condiciones se presentan en los países más pobres africanos donde se desarrolla la epidemia del Ébola.

En su dominio particular, es decir, de los procesos más cercanos que se dan en las comunidades africanas que padecen la enfermedad del Ébola, se da una determinación por sistemas de salud ineficaces y prácticamente inexistentes, que en el marco de economías precarias, han diezmado los sistemas de salud pública que no tienen capacidad de responder a situaciones de salud tan graves como estas ${ }^{15}$. A lo que se suma en este dominio, los procesos de corrupción que se dan y que desvían el uso adecuado de los recursos públicos hacia intereses individuales.

Igualmente en este dominio particular, la explotación agrícola intensiva de los suelos, sumada al conflicto civil, ha generado grandes cambios ecológicos que han contribuido a la creación de nuevos ambientes para la reproducción de patógenos (organismos causantes de enfermedades), hasta ahora desconocidos y confinados a la vida silvestre, que empezaron a infectar a seres humanos ${ }^{17}$.

Así mismo, la pobreza en estos países ha establecido un modo de vida a la gente que les impone adentrarse en la selva en busca de alimentos y leña para combustible, donde entran en contacto con animales que sirven de reservorios, como el caso de los murciélagos de la fruta $^{14}$.

Estos determinantes de dominio general y particular son los que explican que el ébola es una patología social, que no se produce solo por la contaminación con el virus.

\section{DISCUSIÓN}

La epidemia ha revelado la preocupante situación que viven los países africanos que la padecen, el deterioro que sufren sus sistemas de salud y lo abyectos que pueden llegar a ser los sistemas sociopolíticos ante los problemas que aquejan a una comunidad.

Si bien los desastres siempre sacan a relucir los aspectos y valores más inherentes a los seres humanos una 
muestra de ello en este caso es el vasto esfuerzo que han desplegado organizaciones como Médicos sin fronteras (MSF), con recursos físicos y humanos considerables para prestar medidas que contengan la epidemia, de parte de imperios financieros mundiales, que no están interesados en proporcionar estándares de utilización de recursos naturales sustentables, no se puede esperar un cambio en sus políticas, pues están en juego preponderantemente sus intereses económicos.

Más que una enfermedad epidémica, se trata de la manifestación de la patología del sistema sociopolítico que aqueja a los países subdesarrollados, de una enfermedad de la pobreza y la exclusión, del hacinamiento, de la falta de condiciones adecuadas de saneamiento básico, de la despreocupación global por la injustica e inequidad económica que existe en África la misma que causa que los más pobres adquieran la enfermedad en procura de conseguir alimentos en lugares hostiles y que se encarga descuidadamente de dejarlos morir en medio de sistemas deficientes de salud ${ }^{16}$.

¿Cuántas muertes innecesarias más se requerirán, para que el mundo comprenda que lo que se debe atacar centralmente es la desigualdad y la exclusión social para superar este tipo de epidemias?

\section{CONCLUSIÓN}

Se podría considerar que el uso conjunto de la ecografía realizada por un operador avezado y el centellograma MIBI efectuado en centros con complejidad adecuada, son la mejor estrategia diagnóstica para la localización de las glándulas paratiroideas No obstante, según esta casuística, ambos métodos de diagnóstico tuvieron una capacidad diagnóstica que se puede categorizar entre baja y muy baja, tomando en cuenta el área bajo la curva (área ROC), cuyo valor óptimo es igual a 1.0. Debe tenerse en cuenta que la experiencia del cirujano que opera frecuentemente hiperparatiroidismo secundario no ha sido superada aún por la tecnología.

\section{DECLARACIÓN SOBRE CONFLICTOS DE INTERÉS}

Los autores manifiestan no tener ningún conflicto de interés en relación al desarrollo del manuscrito.

\section{REFERENCIAS BIBLIOGRÁFICAS}

1. Centers For Disease Control And Prevention, About Ebola Hemorrhagic Fever| Ebola Hemorrhagic Fever | CDC. (s. f.). Disponible en: http://www.cdc.gov/vhf/ ebola/about.html

2. OMS. «Ebola Situation report - 7 January 2015. Situation reports: Ebola response roadmap. (Consultado el 8 de enero de 2015).

3. World Health Organization (2014), WHO Statement on the Meeting of the International Health Regulations Emergency Committee Regarding the 2014 Ebola Outbreak in West Africa, 8th August 2014. WHO, Geneva. Available at: http://www.who.int/mediacentre/ news/statements/2014/ebola-20140808.

4. Fauci A. Ebola - Underscoring the Global Disparities in Health Care Resources. N Engl J Med. 2014; 371;(12): 1084- 1086

5. Santoni D. El Ébola, la pobreza y los proyectos estratégicos de salud. 2014 disponible en: http://www. veradia.com/nota.php?id $=5775$

6. Chronology of Ebola hemorrhagic fever outbreaks. Atlanta: Centers for Disease Control and Prevention. Disponible en http://www.cdc.gov/vhf/ebola/ resources/outbreak-table.html

7. Rémy J. Nigeria : le pays qui a contré le virus Ebola. Le monde. Disponible en : http://www.lemonde.fr/sante/ article/2014/10/17/le-nigeria-un-exemple-dans-la-luttecontre-ebola_4508031_1651302.html.

8. CIA. (s. f.). The World Factbook. Economy - overview of Sierra Leona. Disponible en: https://www.cia.gov/ library/publications/the-world-factbook/fields/2116. html\#gv

9. Bausch DG, Schwarz L. Outbreak of Ebola Virus Disease in Guinea: Where Ecology Meets Economy. PLoS Negl Trop Dis. 2014; 8(7): e3056. DOI:10.1371/journal. pntd.0003056.

10. Ebola workers at risk: the tragic reality of the Ebola response in West Africa | Médecins Sans Frontières (MSF) International. (s. f.). disponible en: http://www. msf.org/article/ebola-workers-risk-tragic-reality-ebolaresponse-west-africa

11. Mugele J. Priest C. A Good Death - Ebola and Sacrifice. N Engl J Med. 2014; 371; (13): 1185-1186. DOI: 10.1056/ NEJMp1409859.

12. Frieden T, Damon I, Bell B, Kenyon T, Nichol S. Ebola 2014 - New Challenges, New Global Response and Responsibility. N Engl J Med. 2014; 371 (13): 1177-1179. DOI: 10.1056/NEJMp1409903 
13. Gostin L, Friedman E. Ebola: a crisis in global health leadership. Published online October 7, 2014. http:// dx.doi.org/10.1016/S0140-6736

14. People Health Movement's. Position Paper. Ebola epidemic exposes the pathology of the global economic and political system. 2014 Disponible en: http://www. phmovement.org/sites/www.phmovement.org/files/ phm_ebola_23_09_2014final_0.pdf

15. Médecins Sans Frontières. Ebola: the failures of the international outbreak response. 2014. http/www. msf.org/article/ebola-failures-international-outbreakresponse.
16. Tovar-Torres M. ¿Y qué del Ébola en Colombia?. Corporación viva la ciudadanía. 2014 (421). http://viva. org.co/cajavirtual/svc0421/pdfs/Articulo642_421.pdf

17. Virchow R. Reporte sobre la epidemia de tifo en Alta Silesia. Medicina Social. 2008; 3, 1: 5-20.

18. Breilh J. La epidemiología crítica: una nueva forma de mirar la salud en el espacio urbano. Salud Colectiva. 2010; 6 (1): 83-101.

Para citar este artículo: Romero-Rueda J, Torres-Tovar M. Ébola: ¿enfermedad viral o patología social?. Duazary. 2016 enero; 13 (1): 40 - 46 